\title{
ONLINE APPENDIX: Financial Incentives and the Fertility-Sex Ratio Trade-off
}

\author{
By S ANUKRITI
}

This document comprises (i) a theoretical model and (ii) an empirical appendix with additional results.

\section{Model}

This section presents a stylized discrete-choice model to derive predictions about the effects of a financial incentive program that rewards parents that have fewer children and more daughters. For simplicity, assume that (i) the program provides benefits only to parents that have one child, conditional on no second births, and (ii) the benefit received by parents of one girl $(\$ \mathbf{G})$ is larger than the benefit received by parents of a boy $(\$ \mathbf{B}) .{ }^{1}$ Suppose this program is announced in year $t$. Couples that have no children or one child at the time of announcement are, thus, "treated" by the program, whereas the rest are not. However, differences in the future outcomes of couples with dissimilar child compositions in year $t$ cannot be solely attributed to variation in the program's incentives. For example, one-boy families may be less likely to sex-select at higher parities than daughtersonly families even in the absence of incentives. Moreover, characteristics such as son preference that determine the child composition in year $t$ are also likely to influence the effectiveness of incentives in altering childbearing behavior. Thus, the child composition at the start of the program, although pre-determined, is certainly not exogenous.

To take this endogeneity into account, I first analyze the decision-making process in the absence of incentives to derive the optimal strategies for different "types" of couples, where type reflects the two key parameters in the model: a couple's degree of son preference and their cost of children. Since different strategies result in distinct outcomes, by observing a couple's child composition in year $t$, I can deduce the strategy they were following, and thus learn about their type. Thereafter, I examine how the introduction of incentives alters the optimal strategy for different types of couples. Essentially, I compare the equilibrium outcomes for the same type of couples with and without incentives. This ensures that my theoretical predictions can be placed in a causal empirical framework.

\footnotetext{
${ }_{1} \$ \mathbf{G}$ and $\$ \mathbf{B}$ represent the inflation-adjusted, present discounted values of the cash transfers (lumpsum or periodic) or the indirect benefits, such as the cost of school supplies or marriage expenses, provided by the government.
} 


\section{A. Set-up}

Consider a unitary household comprising a couple and its children. ${ }^{2}$ A couple's utility is additively separable in the number of sons, $b$, the number of daughters, $g$, and total consumption, $\mathcal{C}$ :

$$
U(b, g, \mathcal{C})=\delta b+g+V(\mathcal{C})
$$

Son preference of the couple is reflected in the parameter $\delta$. I assume $\delta \geq 1$, which reflects that sons are preferred over daughters. ${ }^{3}$ Couples maximize utility subject to their budget constraint:

$$
\mathcal{C}+(b+g) c+c_{s} s \leq Y+S(b, g)
$$

where $s$ is the number of pregnancies for which sex-selection takes place and $c_{s}>0$ is the fixed cost per instance of sex-selection. Sex-selection includes prenatal sex-detection through ultrasound (or amniocentesis) and potential sex-selective abortion. The gender-invariant cost of a child is $c>0$, which includes the cost of child-rearing as well as the opportunity cost of having children. A couple's exogenous income is $Y$. The price of consumption is normalized to one. There are no spontaneous abortions or still-births. Moreover, all couples have costless access to contraception and all pregnancies are planned. $S(b, g)$ is the incentive payment received from the program, as a function of $b$ and $g$ :

$$
S(0,1)=\mathbf{G}>\mathbf{B}=S(1,0)
$$

The utility function is linear in consumption. Specifically, $V(\mathcal{C})=\mathcal{C}$. Substituting the budget constraint in the utility function and ignoring $Y$ yields:

$$
U(b, g, s)=\delta b+g-(b+g) c-c_{s} s+S(b, g)
$$

Suppose a woman can become pregnant at most twice. This is essentially a simplifying assumption since the program does not provide incentives to couples that have more than one child. In the absence of sex-selection, half of all pregnancies result in a male birth. If a woman opts for an ultrasound test, then she always aborts if the fetus is female. ${ }^{4}$ To mimic the actual programs, all couples

\footnotetext{
${ }^{2}$ I ignore intrahousehold bargaining since both spouses are joint beneficiaries under most existing programs of this type.

${ }^{3}$ For simplicity, $\delta$ captures all factors due to which sons may be relatively more valuable than daughters, e.g., dowry costs and old-age support.

${ }^{4}$ In the absence of incentives, it is clearly sub-optimal to not do so if an ultrasound test is costly. However, when incentives for a girl are higher relative to a boy, it is possible that some couples might
} 
become sterilized after achieving their desired fertility, i.e., the decision about whether and when to become sterilized is not examined separately from other fertility decisions. I also abstract away from factors that determine which spouse becomes sterilized. ${ }^{5}$ Lastly, I ignore the marriage market. ${ }^{6}$

\section{B. Equilibrium without SDT and no financial incentives}

When SDT is unavailable and there are no incentives, decisions about the number of children depend only on the degree of son preference, $\delta$, and the cost of children, $c$.

Proposition 1. In the absence of both SDT and financial incentives, fertility increases in the intensity of son preference and decreases in the cost of children. ${ }^{7}$

In my model, couples for whom children are "not costly" have the maximum possible, i.e., two, births. Among the rest, those with a strong enough son preference also have two children, while the remainder forgo having children altogether. In this scenario, couples cannot guarantee a son through sex-selection. As a result, while deciding to become pregnant, they compare the "risk" of a daughter with the potential "benefit" from a son. They become pregnant only if daughters are not too costly or sons are valuable enough. Note that in this case the sex ratio at birth in the population is balanced, ${ }^{8}$ i.e., son preference manifests itself in terms of fertility in the absence of SDT.

Proposition 1 is also informative about the heterogeneity in fertility across socioeconomic groups in the absence of SDT. For instance, it implies that women whose opportunity cost of childbearing is lower will have higher fertility, conditional on the degree of son preference. Although the marginal utility of children does not vary by income in this model, a simple modification implies that couples with higher marginal utility of children will have higher fertility, given $\delta$ and $c$.

\section{Equilibrium with SDT and no financial incentives}

Availability of SDT expands the choice set of couples. In the absence of SDT, a pregnancy necessarily implies birth and the choice is between a birth or no birth; this is not the case anymore. Now a couple has three choices at each decision node: (a) no pregnancy, (b) pregnancy with an ultrasound test $(U S)$, or (c) pregnancy

find it optimal to abort a boy in order to receive more money. There is no concrete evidence that boys are also selectively aborted in India or China. In the interest of keeping the model tractable, especially since I limit the maximum pregnancies to two, I ignore this possibility.

${ }^{5}$ In both India and China, the prevalence of male sterilization is substantially lower than the rate for females.

${ }^{6}$ Pörtner (2010), independently, uses a similar theoretical set-up to examine the relationship between sex-selective abortions, fertility, and birth spacing in India. However, his paper does not examine the effect of financial incentives on fertility.

${ }^{7} \mathrm{~A}$ discussion of the model assumptions and all proofs appear later.

${ }^{8}$ This is true even if parents follow son-biased stopping rules. In fact, son-biased stopping rules, by themselves, do not imply male-biased sex ratios at birth if parents are homogeneous in the probability of having a boy (Yamaguchi (1989), Goodman (1961)). 
without an ultrasound test. ${ }^{9}$ If (b) is chosen, either a male birth or an abortion (if the fetus is a girl) take place with equal probability. Along with son preference and the cost of children, the equilibrium outcomes now also depend on the cost of sex-selection.

Proposition 2. In the absence of financial incentives, the introduction of SDT increases the sex ratio at birth, but the effect on fertility is ambiguous.

Two types of couples are affected by the availability of SDT. Earlier, some high son preference couples would have had two children in an attempt to have sons, despite a high cost of children (Type 1). SDT allows them to perfectly avoid giving birth to "unwanted" daughters. Thus, fertility declines and the proportion of sons rises (and is equal to 1) for these couples. There is also a second type (Type 2) of couples that would have opted for no births when they could not sex-select. These "intermediate $\delta$ - high $c$ " couples will now find pregnancies with ultrasound tests optimal. Both fertility and the number of sons increase for these couples. ${ }^{10}$ The sex ratio at birth increases for the population as a whole because Type 1 couples have fewer daughters and Type 2 couples have more sons. Thus, this simple framework shows that the availability of SDT unambiguously leads to a higher sex ratio at birth, but fertility may increase or decrease. ${ }^{11}$ If the cost of sex-selection increases, e.g., due to stricter enforcement of bans on sex-selection, fewer couples sex-select and the sex ratio at birth decreases. The opposite happens when it becomes cheaper to sex-select.

\section{Effects of financial incentives when SDT is available}

Along with son preference and the cost parameters, the equilibrium outcomes now also depend on the size of incentives, $S(b, g)$. I start by examining the effect of these incentives on transitional couples that already have one child when the program is announced.

Proposition 3. (a) Transitional couples are less likely to have a second birth due to the incentives.

(b) Those that stop childbearing have a weaker son preference than those that become pregnant again.

(c) Second births are more likely to be male.

The intuition behind Proposition 3 is as follows. In the absence of incentives, all one-child couples would have chosen a second pregnancy (some with $U S$ and others without $U S$ ). This is because (i) utility is linear in the number of children,

\footnotetext{
${ }^{9} \mathrm{~A}$ more realistic, but more complicated, model would allow a couple's choice set to comprise sexdetermination, sex-selective abortion, and discrimination in prenatal and postnatal investments. I ignore these other avenues for expression of son preference and allow parents to either sex-select or not choose sex-determination. Thus, all predictions generated by my model refer to sex ratios at birth.

${ }^{10} \mathrm{Li}$ and Pantano (2014) find a similar result in the context of the United States, where they show that SDT increases fertility because the Type 2 effect is stronger than the Type 1 effect.

${ }^{11} \mathrm{Kim}$ (2005) derives a similar result. However, his argument relies on the relative effect of SDT availability on non-selective abortions, selective abortions, and births without detection. In his model, fertility rises if more selective abortions are performed at the expense of non-selective abortions. On the other hand, if more women have selective abortions instead of births without detection, fertility falls.
} 
and (ii) these couples are not "high $c$ - low $\delta$ " types (that never become pregnant) since they already have a child. Introduction of one-child incentives makes it optimal for some of these couples to not become pregnant again, resulting in $3(a)$. Larger incentives for one child or a higher utility from incentives (if couples varied in terms of marginal utility of income) will decrease the likelihood of a second pregnancy even more.

Moreover, ultrasound test is now more likely to be used for the second pregnancy for two reasons. First, there is selection into second pregnancy by relatively high son preference couples (from $3(b)$ ), that are more likely to use ultrasound tests even in the absence of incentives. Second, the one-child incentives reduce the effective cost of sex-selection for second pregnancies. If a couple finds out that the second child is a girl and aborts, they still receive $\$ \mathbf{G}$ or $\$ \mathbf{B}$ through the program. Otherwise, they are guaranteed a boy that is more valuable for them than couples that stop at one child.

This increased use of ultrasound tests for second pregnancies underlies $3(c)$ and also contributes towards fewer second births in $3(a)$. The increase in the sex ratio at second birth is larger for a lower cost of sex-selection, relative to the size of incentives.

Differential effect on one-boy and one-girl couples. In Proposition 3, the direction of effects is the same for all one-child couples, irrespective of the sex of the first child, but the magnitudes might differ. The incentive amount to stop childbearing is larger for one-girl couples. If the society mainly comprises couples that never choose $U S$, one-girl couples may be more likely to not have a second child as compared to one-boy couples. This increases the proportion of one-girl couples more than the proportion of one-boy couples. In other words, the likelihood of a second birth decreases more for one-girl couples. However, Proposition 2 implies that while one-girl couples must necessarily be those that were following the no US strategy, one-boy couples also include those that were following the $U S$ strategy before the program. These couples selected the sex of their first birth and only the one-boy incentives are relevant for them. For certain distributions of $c$ and $\delta$, there are more one-boy couples that were sex-selecting before the program and stop childbearing due to the $\$ \mathbf{B}$ incentive than couples were following a no US strategy before the program and stop childbearing if they have a girl but not if they have a boy. In this case, more couples stop after one boy than after one girl. ${ }^{12}$

Next I examine couples that were childless in year $t$. Within this group, it is important to distinguish childless couples that were following the $U S$ strategy and had aborted their first girl from those that had not begun childbearing by year $t$, e.g., due to marriage after year $t$. In the absence of incentives, the former group

\footnotetext{
${ }^{12}$ Note that, if at least some people select at first birth, then there will be more one-boy couples than one-girl couples to begin with. Additionally, even in the absence of incentives, one-boy couples are less likely to have a second birth and their second child is more likely to be a boy because more of them choose US than one-girl couples. But after the program, the likelihood of a second birth will decrease more for one-boy couples for certain distributions of $c$ and $\delta$.
} 
would have aborted again if the second pregnancy was female, but now some of them might find it optimal to choose no US. For this group, the likelihood of remaining childless decreases and their first-born is more likely to be a girl.

Proposition 4. Childless women that previously had one abortion are more likely to give birth and this child is more likely to be a girl.

The above effect is driven by 'intermediate- $\delta$ ' couples for whom the cost of children is high relative to the cost of sex-selection (which is why they were selecting before), however, the $\$ \mathbf{G}$ incentive is large enough to overcome the cost of a potential girl. Proposition 4 rests on the fact that these women have only one more chance to become pregnant since I limit the maximum number of pregnancies to two. In terms of testable predictions, this group can be thought of as women approaching the end of their fertile years.

To determine the effect of incentives on couples that begin childbearing after the program's announcement, I solve for their optimal strategies through an exercise similar to the proof of Proposition 2, but with incentives. This is the relevant treatment group for understanding the long-run effects of the program. In light of the discussion so far, the intuition behind the predictions for these couples is straightforward albeit the proof is computationally complex. ${ }^{13}$ For given cost parameters, high- $\delta$ couples find it optimal to have just one child with sex-selection, whereas low- $\delta$ couples have one child without sex-selection. For a given degree of son preference, the incentives will reduce fertility more for couples with a higher cost of children.

Proposition 5. For couples that begin childbearing after the program's announcement: (a) Fertility decreases and the proportion of one-child families increases. (b) The effect on the sex ratio at first birth is ambiguous and depends on the distribution of $c$ and $\delta$.

\section{E. Implications for Devi Rupak}

Devi Rupak is similar to the hypothetical program analyzed in the model. The only difference is that Devi Rupak also provides $\$ \mathbf{B}$ to parents that have two daughters and no sons. The two-girls benefit modifies the predictions for "transitional couples," but only slightly. Ultrasound tests and abortions are relatively cheap in India and each costs around Rs. 500-Rs. 1,000 (USD 8 - USD 16) (Arnold, Kishor and Roy (2002)). Thus, the cost of sex-selection is substantially smaller than the incentive amounts. The two-girls benefit increases the utility from choosing the no US option for one-girl transitional couples. Thus, in Devi Rupak's case, one-girl couples (relative to one-boy couples) experience a smaller decrease in the likelihood of another birth and a smaller increase in the probability of next birth being male, as compared to the hypothetical program. All other predictions remain the same.

To summarize, my model yields the following testable implications:

\footnotetext{
${ }^{13}$ Due to its computational complexity, this proof is not presented here, but is available upon request.
} 
1) High son preference and high cost of children couples have higher sex ratios before Devi Rupak since SDT was widely available in India much before 2002 (Bhalotra and Cochrane (2010)).

2) Devi Rupak reduces the probability of a second birth for couples that had one child in 2002.

3) For couples that had one child in 2002, second births are more likely than earlier to be male.

4) Childless women approaching the end of their fertile years are more likely to give birth and this child is more likely to be a girl than earlier.

5) Couples that begin childbearing after 2002 are more likely to have only one child and have fewer children than earlier.

6) The sex ratio of first birth increases for couples that start childbearing after 2002 if their son preference is strong enough.

\section{F. Discussion of assumptions}

I have made several assumptions in my model to highlight the implications of financial incentive programs in the simplest manner. In this section, I discuss some key assumptions about the utility function and show that the simplifications do not come at the expense of generality.

In my model, the utility function is linear and separable in $b$ and $g$. However, some parents may follow son-biased stopping rules due to a desire for a minimum number of sons, or prefer a mixed sex-composition. In such cases, a non-separable utility function might be more appropriate. However, the introduction of sonbiased stopping rules in the model will not alter the basic theoretical predictions. In fact, if parents desire at least one son, the one-girl incentives will clearly be less effective than they are in my model, and couples will be even more likely to choose the one-boy option. A preference for a mixed sex-composition would similarly make the program less effective since couples that have both boys and girls receive no benefits.

One consequence of the functional form assumption in the model is that couples either always sex-select or never sex-select in the absence of incentives, irrespective of birth parity. It might appear that the prediction about one-boy couples being more likely to stop childbearing than one-girl couples is driven by this. In reality, there is evidence that first births in India are not selected, while higher parity births are. This could reflect a preference for having children of both sexes or a lack of aversion for at most $x$ daughters, both of which imply that couples start selecting from $x+1$ parity onwards. But even if the model allows couples to desire at least one son and at most one daughter, for example, one-boy transitional families would still be more likely to stop childbearing than one-girl transitional 
families, as long as the $\$ \mathbf{G}$ incentive does not sufficiently compensate for the "lost" son. Thus, this prediction holds for more general utility functions as well.

I also assume that the utility function is linear in consumption, i.e., the marginal utility derived from children is independent of income. However, this does not imply that differences in socioeconomic characteristics across couples are irrelevant in this model. Instead, these characteristics affect equilibrium outcomes through the cost of children, $c$, and the intensity of son preference, $\delta$, which are the two dimensions along which couples are allowed to differ.

\section{G. Proofs}

Proof of Proposition 1: Since the maximum number of pregnancies is two, a couple has three choices: zero, one, or two children. I solve for the equilibrium by backward induction. Conditional on having one child, a couple can either choose to stop childbearing (Stop) or have a second child (Birth). The difference between utility from Birth and Stop is independent of the sex of their first child, and is given by:

$$
\Delta U=U(\text { Birth })-U(\text { Stop })=0.5+0.5 \delta-c
$$

If $\delta \geq 2 c-1$, then $U($ Birth $) \geq U($ Stop $)$. Otherwise, Stop is preferred over Birth.

Since $\delta \geq 1$ and $c>0$, there are three possible scenarios:

Case 1: $c \leq 1 \Longrightarrow 2 c-1 \leq 1 \leq \delta \Longrightarrow \Delta U \geq 0$.

Case 2: $c>1$ and $\delta \geq 2 c-1 \Longrightarrow \Delta U \geq 0$.

Case 3: $c>1$ and $\delta<2 c-1 \Longrightarrow \Delta U<0$.

The same choices are optimal at the first decision node, i.e., the decision about the first pregnancy. In equilibrium, Case 3 couples have no children and the rest have two children. Proposition 1 is illustrated in Figure 1.

Proof of Proposition 2: Let $U(S t o p)$ denote utility if a couple stops childbearing after their first pregnancy. Utility from a second pregnancy with and without an ultrasound test is given by:

$$
\begin{array}{r}
U(U S)=U(S t o p)+0.5\left(\delta-c_{a}-c\right)-c_{u} \\
U(N o U S)=U(\text { Stop })-c+(1+\delta) / 2
\end{array}
$$

where $c_{u}$ and $c_{a}$ are the costs of an ultrasound test and an abortion, respectively. Define $c_{s}^{\prime}=2 c_{s}=2 c_{u}+c_{a}$, where $c_{s}$ is the cost of sex-selection.

If $\delta>c+c_{s}^{\prime}$, then $U S \succ$ Stop. If $\delta>2 c-1$, then No US $\succ$ Stop. If $c<1+c_{s}^{\prime}$, then No US $\succ U S$.

Case 1: $c \leq 1 \Longrightarrow c<1+c_{s}^{\prime} \Longrightarrow$ No US $\succ U S$. Also, $c \leq 1 \Longrightarrow 2 c-1 \leq$ $1 \leq \delta \Longrightarrow$ No US $\gtrsim$ Stop. These couples choose a second pregnancy without $U S$. 


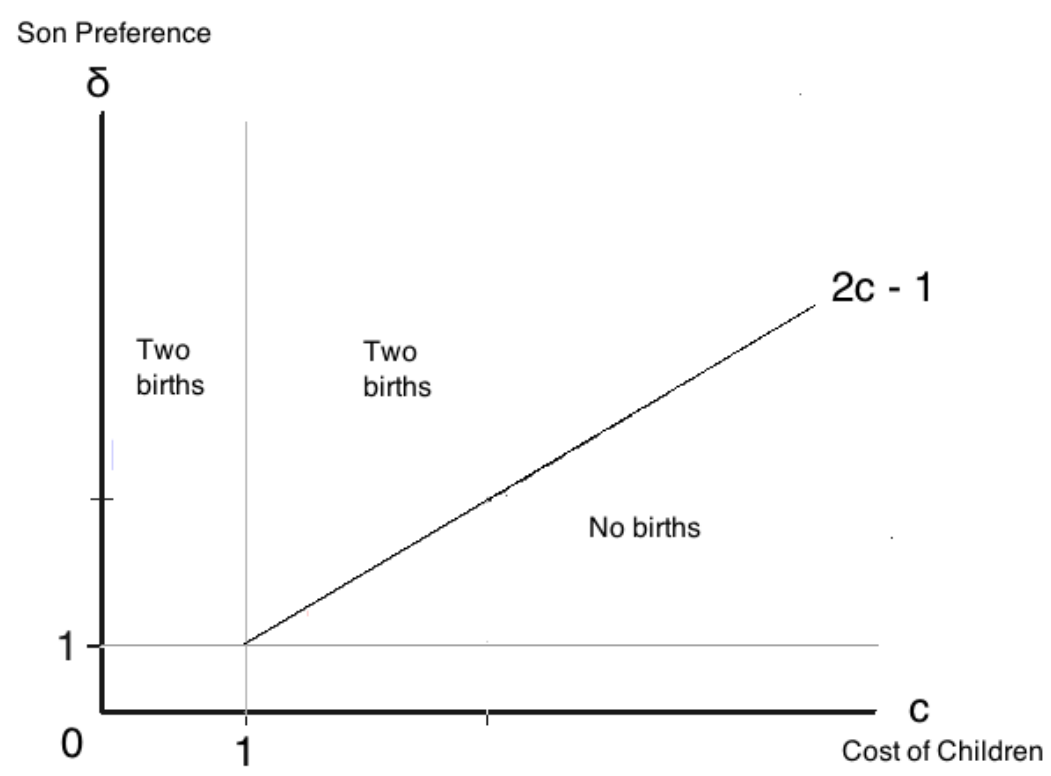

Figure 1. Equilibrium in the abSence of SDT and incentives

Case 2: $1<c \leq 1+c_{s}^{\prime} \Longrightarrow N o U S \gtrsim U S$. If $\delta>2 c-1>1$, they choose a second pregnancy without $U S$ and if $\delta \leq 2 c-1$, they stop childbearing.

Case 3: $c>1+c_{s}^{\prime} \Longrightarrow U S \succ N o$ US. If $\delta>c+c_{s}^{\prime}$, they choose a second pregnancy with $U S$ and if $\delta \leq c+c_{s}$, they stop childbearing.

The same choices are optimal at the first decision node i.e., the decision about the first pregnancy. Thus, couples in Case 1 choose two pregnancies without $U S$. In Case $2, \delta<2 c-1$ couples never become pregnant, and the remaining choose two pregnancies without $U S$. In Case 3, couples with $\delta \leq c+c_{s}$ never become pregnant and those with $\delta>c+c_{s}^{\prime}$ choose two pregnancies with $U S$. Proposition 2 is illustrated in Figure 2

Proof of Proposition 3: This proof has two parts. Part 1 analyzes the effect of the program on couples that had one boy in year $t$. Part 2 examines couples that had one girl in year $t$.

\section{Part 1: One-boy couples}

Three types of couples can possibly have one boy (and no girl) when the program starts:

Type A: $c \leq 1$

Type B: $1<c \leq 1+c_{s}^{\prime}$ and $\delta>2 c-1$

Type C: $c>1+c_{s}^{\prime}$ and $\delta>c+c_{s}^{\prime}$ 


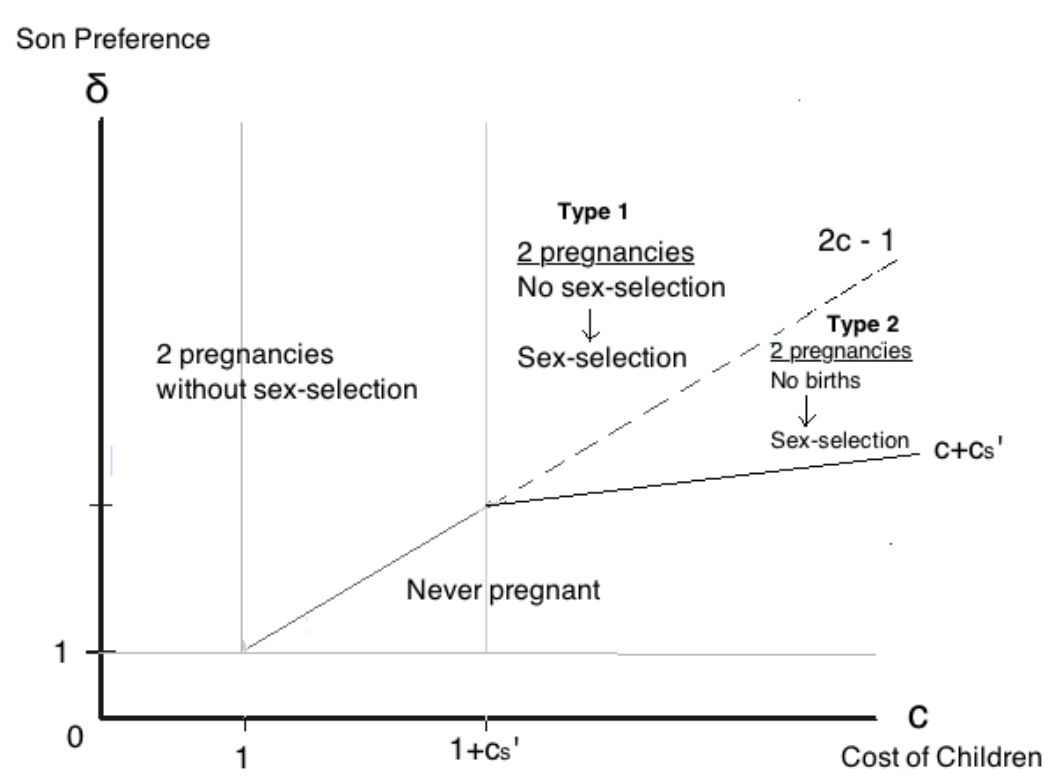

Figure 2. Equilibrium with SDT and without incentives

In the absence of the program, all types would have chosen a second pregnancy - Types A and B without US and Type $\mathrm{C}$ with $U S$. After the program, they face the same three choices as before, but with incentives. The additional utility from each option, conditional on already having a boy, is:

$$
\begin{gathered}
\Delta U(U S)=-c_{u}+0.5\left(-c_{a}+\mathbf{B}\right)+0.5(\delta-c) \\
\Delta U(n o U S)=0.5+0.5 \delta-c \\
\Delta U(\text { Stop })=\mathbf{B}
\end{gathered}
$$

If $c>1+c_{s}^{\prime}-\mathbf{B}$, then $U S \succ N o$ US. If $\delta<2 c-1+2 \mathbf{B}$, then Stop $\succ$ No US. If $\delta<c+c_{s}^{\prime}+\mathbf{B}$, then Stop $\succ U S$.

For Type $\mathrm{C}$ couples, $U S \succ N o$ US even after the incentives. But those with $c+c_{s}^{\prime}<\delta<c+c_{s}^{\prime}+\mathbf{B}$ will switch from $U S$ to Stop. The remaining Type C couples will continue with $U S$ as before. Thus, for Type $\mathrm{C}$ couples as a whole, fertility and the number of sons decrease. The proportion of sons remains the same (equal to 1) since they were going to have only boys even without the incentives.

For Types $\mathrm{A}$ and $\mathrm{B}$, there are two scenarios:

Case 1: $1+c_{s}^{\prime}-\mathbf{B}<1$, i.e., $c_{s}^{\prime}<\mathbf{B}$. Type A couples with $c<1+c_{s}^{\prime}-\mathbf{B}$ still prefer no US to $U S$. They Stop if $\delta<2 c-1+2 \mathbf{B}$, otherwise continue with 
no $U S$ as before. Type A couples with $1+c_{s}^{\prime}-\mathbf{B}<c<1$ prefer $U S$ over no $U S$. They Stop if $\delta<c+c_{s}^{\prime}+\mathbf{B}$, otherwise choose US. Similarly, for all Type B couples, $U S \succ N o U S$. They Stop if $\delta<c+c_{s}^{\prime}+\mathbf{B}$, otherwise opt for US. Thus, some Type A and all Type B change their optimal strategy. Fertility falls and the proportion of sons rises for both Types A and B. Moreover, their second child is more likely to be a boy because some of them now opt for US.

Case 2: $1+c_{s}^{\prime}-\mathbf{B} \geq 1$, i.e., $c_{s}^{\prime} \geq \mathbf{B}$. In this case, all Type A couples still prefer no $U S$ to $U S$. If $\delta<2 c-1+2 \mathbf{B}$, they Stop, otherwise continue with no $U S$ as before. For Type $\mathrm{B}$ couples with $1<c<1+c_{s}^{\prime}-\mathbf{B}$, no US is preferred over $U S$. If $\delta>2 c-1+2 \mathbf{B}$, they continue with no US. However, if $2 c-1<\delta<2 c-1+2 \mathbf{B}$, they Stop. For the remaining Type B couples, US is now preferred over no US; they Stop if $\delta<c+c_{s}^{\prime}+\mathbf{B}$, otherwise choose $U S$. Fertility falls and the proportion of sons rises for both Types A and B. Moreover, the second child for Type B couples is more likely to be a boy because some of them now choose US.

These findings can be summarized as follows:

\begin{tabular}{ccccc}
\hline Type & Fertility & Proportion of sons & \multicolumn{3}{c}{ 2nd birth is male } \\
\cline { 3 - 5 } & & & $c_{s}^{\prime}<\mathbf{B}$ & $c_{s}^{\prime} \geq \mathbf{B}$ \\
\hline $\mathrm{A}$ & - & + & + & No change \\
$\mathrm{B}$ & - & + & + & + \\
$\mathrm{C}$ & - & No change & \multicolumn{2}{c}{ No change } \\
\hline
\end{tabular}

Figure 3 illustrates the new equilibrium choices. Couples in the grey region stop childbearing after the program, i.e., fertility declines for them. Their proportion of sons increases since some of them were following a no US strategy and may have had a girl before the program. Couples in the black region switch from no $U S$ to $U S$ for their second pregnancy. For them, fertility decreases and their second child is more likely to be a boy, i.e., the proportion of sons rises. The remaining couples with one boy continue with their original strategy.

In both Cases 1 and 2, the incentive increases the probability that couples that had one boy in year $t$ stop childbearing. Moreover, it encourages some high son preference couples to switch from no $U S$ to $U S$ in case of a second pregnancy. This is because the incentive reduces the net cost of selection. Both these effects are stronger when $\mathbf{B}$ is larger relative to $c_{s}^{\prime}$. Moreover, larger incentives for one child or a higher utility from incentives (if couples varied in terms of marginal utility of income), decrease the likelihood of a second pregnancy, for given cost parameters and son preference.

How do couples that stop childbearing differ from those that become pregnant again? Within Type $\mathbf{C}$, those with $\delta<c+c_{s}^{\prime}+\mathbf{B}$ stop and the rest become pregnant again. Thus, for a given $c$ (and $c_{s}^{\prime}$ ), couples that have a second birth will have a stronger son preference than those that choose Stop. The same is true for Types A and B.

\section{Part 2: One-girl couples}



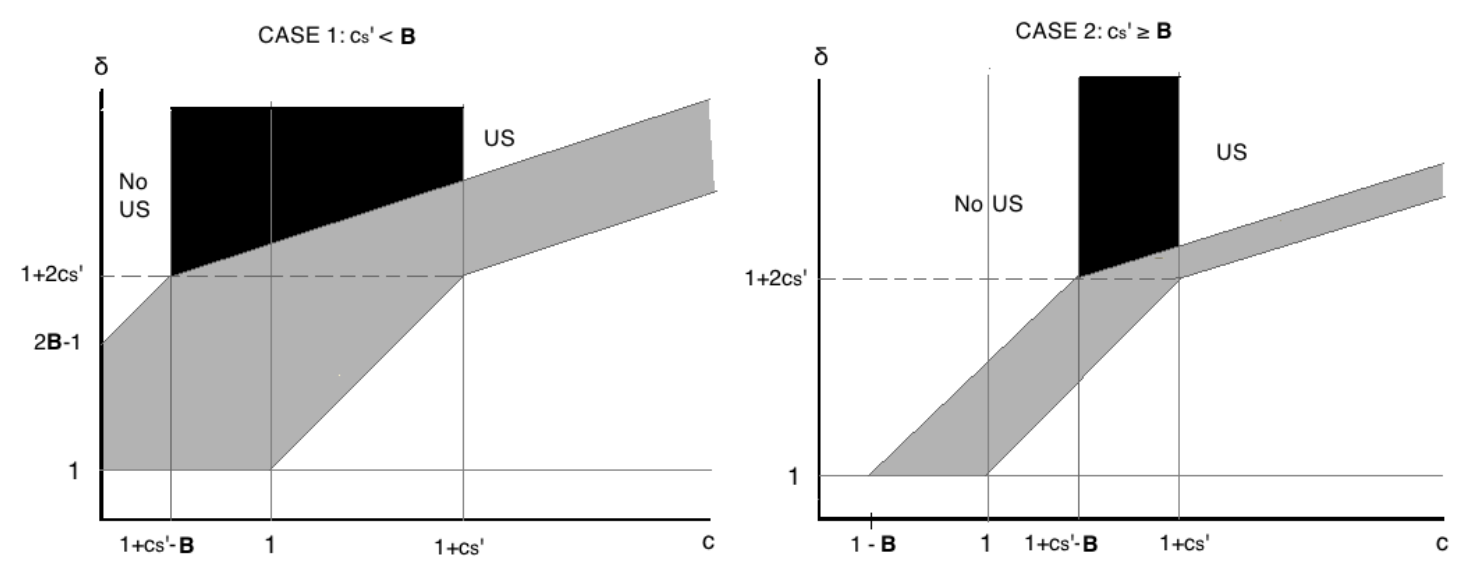

Figure 3. EFFECt on COUPles that had one SON AND NO DAUGHTERS IN 2002

Note: Couples in the grey region stop childbearing. Those in black have a second child, that is more likely to be male than in the absence of incentives. For expositional purposes, the left panel has been drawn under the assumption that $1>\mathbf{B}-c_{s}^{\prime}$ and the right panel assumes that $1>\mathbf{B}$. However, neither is necessary for Proposition 3.

Two types of couples can possibly have one girl when the program starts:

Type A: $c<1$

Type B: $1<c<1+c_{s}^{\prime}$ and $\delta>2 c-1$

In the absence of incentives, both types would have chosen a second pregnancy without US. The additional utility from the three available choices, conditional on already having a girl, is as follows:

$$
\begin{gathered}
\Delta U(\text { Stop })=\mathbf{G} \\
\Delta U(U S)=-c_{u}+0.5(\delta-c)+0.5\left(-c_{a}+\mathbf{G}\right) \\
\Delta U(n o U S)=0.5+0.5 \delta-c
\end{gathered}
$$

If $c>1+c_{s}^{\prime}-\mathbf{G}$, then $U S \succ N o$ US. If $\delta<2 c-1+2 \mathbf{G}$, then Stop $\succ$ No US. If $\delta<c+c_{s}^{\prime}+\mathbf{G}$, then Stop $\succ U S$.

Case 1: $1+c_{s}^{\prime}-\mathbf{G}<1$, i.e., $c_{s}^{\prime}<\mathbf{G}$. If $c<1+c_{s}^{\prime}-\mathbf{G}$, No $U S \succ U S$. Stop is chosen if $\delta<2 c-1+2 \mathbf{G}$, otherwise Type A couples continue with $N o$ $U S$. If $1+c_{s}^{\prime}-\mathbf{G}<c<1, U S \succ$ no US. These Type A couples choose Stop if $\delta<c+c_{s}^{\prime}+\mathbf{G}$, otherwise they switch to $U S$. Type B couples also prefer $U S$ to no $U S$ now, and choose Stop if $2 c-1<\delta<c+c_{s}^{\prime}+\mathbf{G}$, and otherwise switch to $U S$. Note that stopping at one girl implies a decrease in the proportion of sons because these couples were following a no US strategy before. Fertility decreases for both types. The proportion of sons declines for some Type A couples $\left(c<1+c_{s}^{\prime}-\mathbf{G}\right)$, but the effect is ambiguous for the remaining Type A couples $\left(1+c_{s}^{\prime}-\mathbf{G}<c<1\right)$ and all Type B couples. This is because the couples that choose Stop experience 
a decline in the proportion of sons, but those that have a second child with $U S$ have a larger proportion of sons.

Case 2: $1+c_{s}^{\prime}-\mathbf{G} \geq 1$, i.e., $c_{s}^{\prime} \geq \mathbf{G}$. For Type A couples, No US $\succ U S$. They choose to Stop if $\delta<2 c-1+2 \mathbf{G}$, otherwise they continue with No US. The same holds for Type B couples with $c<1+c_{s}^{\prime}-\mathbf{G}$. But Type B couples with $c>1+c_{s}^{\prime}-\mathbf{G}$ now prefer $U S$ over No US. They Stop if $\delta<c+c_{s}^{\prime}+\mathbf{G}$, otherwise change to $U S$. Fertility decreases for both types. The proportion of sons declines for Type A, but the effect is ambiguous for Type B couples.

These findings can be summarized as follows:

\begin{tabular}{lcccccc}
\hline Type & Fertility & \multicolumn{2}{c}{ Proportion of sons } & & \multicolumn{2}{c}{ 2nd birth is male } \\
\cline { 3 - 4 } \cline { 5 - 7 } & & $c_{s}^{\prime}<\mathbf{G}$ & $c_{s}^{\prime} \geq \mathbf{G}$ & & $c_{s}^{\prime}<\mathbf{G}$ & $c_{s}^{\prime} \geq \mathbf{G}$ \\
\hline $\mathrm{A}$ & - & $+/-$ & - & & + & No change \\
$\mathrm{B}$ & - & \multicolumn{2}{c}{$+/-$} & & \multicolumn{2}{c}{+} \\
\hline
\end{tabular}

Figure 4 illustrates the new equilibrium choices for one-girl couples. Those in the grey region stop childbearing, i.e., fertility declines for them. Couples in the black region were going to have a second child without $U S$ in the absence of the program, but now opt for an $U S$. For them, fertility decreases and their second child is more likely to be a boy.
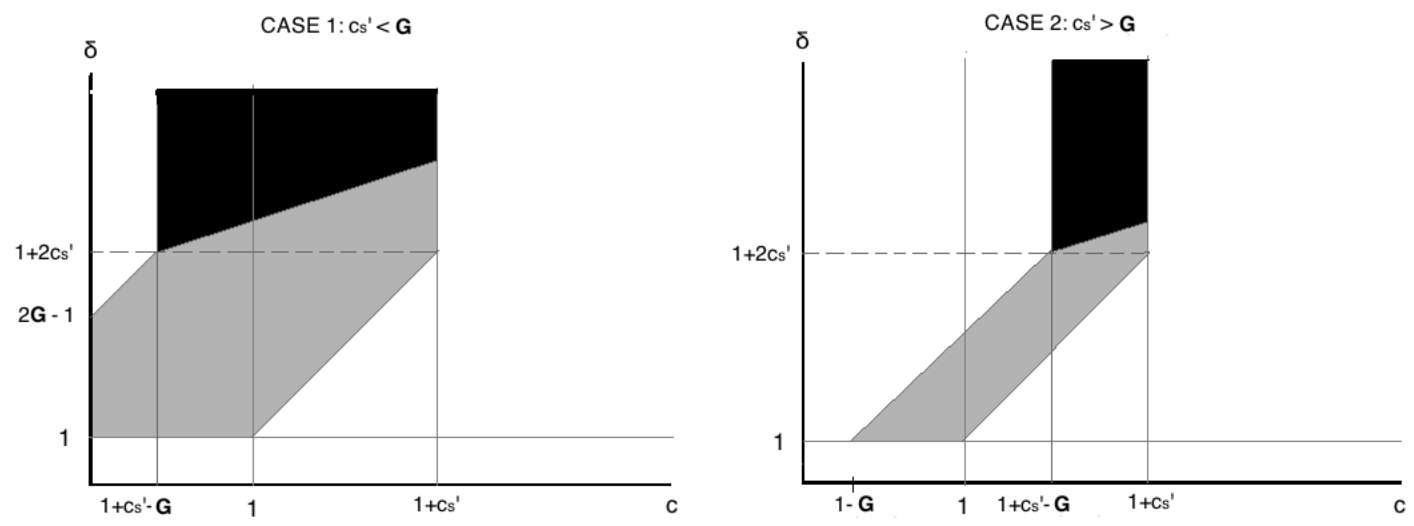

Figure 4. EfFect on COUples that had one DAUghter AND NO SONS IN 2002

Note: Couples in the grey region stop childbearing. Those in the black region have a second child that is more likely to be male than in the absence of incentives.

Proof of Proposition 4: In the absence of incentives, childless women that previously had one abortion $\left(c>1+c_{s}^{\prime}\right.$ and $\delta>c+c_{s}^{\prime}$ for them) would have continued with their $U S$ strategy. As a result, they would have either remained childless or had a boy at the end of their fertile period. After Devi Rupak, their 
utilities from the three options are:

$$
\begin{gathered}
\Delta U(\text { Stop })=0 \\
\Delta U(U S)=-c_{u}+0.5(\delta-c+\mathbf{B})-0.5 c_{a} \\
\Delta U(n o U S)=0.5(\delta+\mathbf{B})+0.5(1+\mathbf{G})-c
\end{gathered}
$$

Since $\delta>c+c_{s}^{\prime}-\mathbf{B}$ for these couples, $U S \succ$ Stop. If $c>1+c_{s}^{\prime}+\mathbf{G}, U S \succ N o$ $U S$. Thus, couples with $1+c_{s}^{\prime}<c<1+c_{s}^{\prime}+\mathbf{G}$ switch from US to no US. They are now less likely to remain childless and more likely to have a daughter than before. Figure 5 indicates them in grey.

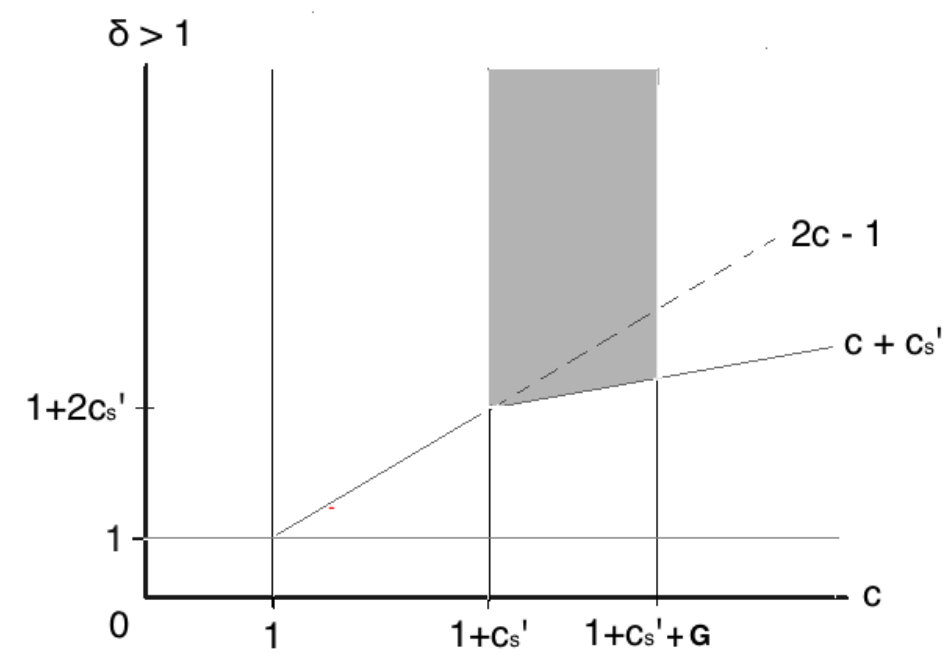

Figure 5. Effect of Incentives on Childless Couples with a Previous Abortion

\section{H. Discussion of alternate programs}

The analysis thus far has established that Devi Rupak's financial incentives successfully decrease fertility and induce couples to have only one child. However, the program unintentionally worsens the sex-imbalance in Haryana for first and second births. Devi Rupak's incentive structure has two key features: (1) it rewards couples that have no daughters, and (2) it does not reward couples that have children of both sexes. ${ }^{14}$ Consequently, a strong desire for at least one

\footnotetext{
${ }^{14}$ Since childless couples receive nothing, unintentionally, Devi Rupak also incentivizes parents to have
} at least one child, which is contrary to the program's stated objective of decreasing fertility. However, 
son suppresses the take-up rates for the girls-only options and makes the one-boy option more attractive despite substantial differences in monetary benefits. Are programs that relax these eligibility criteria, such as the Ladli Laxmi Scheme, likely to perform better? Due to data availability constraints, I cannot empirically evaluate these newer programs, however, my theoretical model can provide guidance about their effects.

No incentive for one-boy couples. Suppose $\mathbf{B}=0$. Such a program will affect childless and transitional one-girl couples. Proposition 3 still holds - fertility should decrease and the sex ratio at second birth should increase for one-girl transitional couples. Devi Rupak's experience suggests that the fertility effect is likely to be small while the increase in sex ratio could be significant. The longrun effect would be driven by childless couples. Among them, the program should increase the likelihood of one girl for low- $\delta$ and high- $c$ couples. The overall sex ratio at first birth would decrease if the proportion of low- $\delta$ and high- $c$ couples is large enough. Thus, programs that do not reward one-boy couples are better in terms of avoiding the unintended increase in the sex ratio at second birth for one-boy transitional couples and the sex ratio at first birth. However, they are also likely to be less effective in reducing fertility as high- $\delta$ couples no longer have the incentive to sex-select at first parity and can "afford" to have more than one child in order to have at least one son.

Incentive for a mixed composition. Next suppose that, in addition to parents of one girl, the program also provides $\mathbf{G}$ to couples that have one boy and one girl, and $\mathbf{B}=0$. Unlike Proposition 3, fertility increases and the proportion of sons decreases for transitional one-boy couples as they are less likely to sexselect their second pregnancy relative to no program. ${ }^{15}$ Transitional one-girl couples are less likely to have a second pregnancy and more likely to practice sex-selection for second pregnancies as in Proposition 3, however, the magnitudes are different. The decrease in the likelihood of second pregnancy is smaller and the probability of sex-selection for second pregnancy higher than it is with Devi Rupak. Additionally, if two-girl couples also receive $\mathbf{G}$, both the increase in the probability of sex-selection for second pregnancy and the decrease in the likelihood of second pregnancy would be smaller. For couples that begin childbearing after the program, the proportion of boys decreases, but the overall effect on fertility depends on the distribution of $c$ and $\delta$. For intermediate- $c-$ high- $\delta$ couples, fertility may increase as they are more likely to have both a boy and a girl instead of just one boy. ${ }^{16}$ These results suggest that programs like Ladli Laxmi are not

only a small fraction of Indian women at the end of their fertile years report being childless, e.g., in 2002-04 about 1 percent of currently-married women in the 40-44 age group in Haryana had never given birth. Since this includes at least some women that are childless due to infertility, the fraction of women that voluntarily remain childless is even lower. Hence, incentivizing couples to remain childless is unlikely to be an important margin of influence on the overall fertility rate.

${ }^{15}$ Formal proofs of these results are available upon request.

${ }^{16}$ This is similar to the effect of the modified "1.5-Child Policy" that allows parents of one girl to have a second child of either sex. Qian (2009) shows that this policy lowered the sex ratio to the pre-OCP level, but it also increased family size. 
necessarily better than Devi Rupak in resolving the fertility-sex ratio trade-off, especially as desired or mandated fertility gets closer to one or two children.

Other crucial aspects of these programs are the magnitude of benefits and how often they are disbursed. Certain programs make the benefits available only after the daughter has turned 18, and in many cases, the beneficiary is the daughter rather than the parents. In contrast, Devi Rupak directly incentivizes the parents, that start receiving the benefits as soon as they become sterilized. To the extent that parents are myopic and discount the future, an immediate and steady stream of benefits is more likely to be persuasive than a lump-sum payment almost two decades later. Thus, programs that provide smaller lump-sum transfers several years into the future, as compared to Devi Rupak, are even less likely to be effective.

\section{Empirical Appendix}

\section{A. Additional sample-selection criteria}

First, for consistency across rounds, I limit my sample to currently-married women in the 15-44 age-group at the time of survey. ${ }^{17}$ Second, I exclude women whose first child was born before they were 13 years old and those that have fertility greater than 10 to prevent any composition bias since these mothers are likely to be fundamentally different from rest of the sample. Third, I exclude women that have had twin or multiple births since these births are mostly unplanned and do not reflect parents' fertility preferences. Fourth, I drop women whose husband's age was below 15 or above 80 at the time of survey. Fifth, I exclude women that were visiting the household when the survey took place, and were interviewed as a result, since there is no information on their actual state of residence. Lastly, DLHS-2 top-codes the year of sterilization as eight years before the survey for women that had been sterilized for more than eight years at the time of survey. As a result, it will artificially appear that DLHS-2 women became sterilized later than comparable women in other rounds. In specifications where the exact year of sterilization is used, I restrict my sample to women that had been sterilized for less than 8 years at the time of survey to address this issue. My results are not driven by any of these criteria.

\section{B. Prediction 1}

Prediction 1 of the model is that couples with a stronger preference for sons and a higher cost of children are more likely to sex-select when SDT is available. Therefore, I expect these couples to have fewer children and a higher proportion of sons during the pre-Devi Rupak years. As an illustrative exercise, I examine

\footnotetext{
${ }^{17}$ Survey questionnaires were administered to 13-49-year old ever-married women in NFHS-1, 15-49year old ever-married women in NFHS-2,3, and 15-44-year old currently-married women in DLHS- 2 .
} 
the cross-section of women interviewed in 1998-99 for NFHS-2 and compare the average proportion of sons and the average number of living children for various socioeconomic groups. ${ }^{18}$ While it is difficult to a priori know which groups have a higher degree of son preference, previous literature suggests that high-caste Hindus, Sikhs, and land-owning families are more likely to, and Muslims are less likely to prefer sons over daughters. ${ }^{19}$ In terms of the opportunity cost of children, I expect more educated women from wealthy families in urban areas to have better labor market opportunities, and hence a higher opportunity cost of children. I divide women into overlapping socioeconomic groups based on these characteristics and calculate the average number of children and the average proportion of sons for each group.

Table 1 lists these groups in decreasing order of the average proportion of sons. A few broad patterns emerge. Women who have more than primary education, who work outside the home and who belong to Sikh, high-caste Hindu, rich, and (agricultural) land-owning households have, on average, a higher proportion of sons and fewer living children than women who work from home, and who belong to poor, low-caste, uneducated, landless, and Muslim families. The highest sex ratios are reported by rural Sikh landowners, rural rich, and relatively educated high-caste Hindu women from wealthy families in urban areas. Similarly, fertility levels are lowest for the same socio-economic groups. This admittedly crude comparison, nevertheless, provides evidence in favor of Prediction 1 from my model. Moreover, it reveals information about the correlations between socioeconomic characteristics and son preference that is useful when I later examine the heterogeneous effects of Devirupak.

\section{Proposition 3(b)}

According to Proposition 3(b), conditional on having a child in 2002, couples that stop childbearing have a weaker son preference or a higher cost of children, relative to those that become pregnant again despite the risk of losing the onechild incentives. To test this prediction, I restrict my sample to couples that had a child in period $(t-3)$ and compare the characteristics of those that gave birth again in period $t$ with those that did not, separately by the sex of the first child, before and after 2002 in Haryana, relative to control states. Table 2 shows that women in Haryana that had one child in $(t-3)$ and stop childbearing after 2002 are less likely to belong to land-owning, rural, high-caste, Hindu families relative to women that have another birth. On the other hand, they are more likely to come from poor, rural, low-caste, Hindu families. Similarly, I find that couples that stop after one child, irrespective of its sex, are more likely to be Muslim. In addition, they are more likely to belong to poor SC households and

\footnotetext{
${ }^{18}$ SDT was widely available in India by 1998-99 (Bhalotra and Cochrane (2010)).

${ }^{19}$ Tambiah (1973), Dickenmann (1979), Oldenburg (1992), Bhat and Zavier (2003), Bhalotra and Cochrane (2010).
} 
Table 1-Sample means Before Devi Rupak, NFHS-2

\begin{tabular}{|c|c|c|c|c|}
\hline Socioeconomic Category & Proportion of sons & $\mathrm{N}$ & \# Living Children & $\mathrm{N}$ \\
\hline Rural Sikh Landowner & 0.5781 & 658 & 2.25 & 718 \\
\hline Sikh & 0.5716 & 1,452 & 2.36 & 1,608 \\
\hline Urban Poor & 0.5616 & 648 & 3.10 & 722 \\
\hline Rural Rich & 0.5556 & 1,783 & 2.34 & 2,020 \\
\hline Rich & 0.5543 & 6,906 & 2.32 & 7,672 \\
\hline Urban Rich & 0.5538 & 5,123 & 2.31 & 5,652 \\
\hline$>6$ years of education & 0.5532 & 7,124 & 1.94 & 8,279 \\
\hline Rich, Educated, High-caste, Urban Hindu & 0.5510 & 2,494 & 1.96 & 2,751 \\
\hline High-caste & 0.5496 & 12,279 & 2.63 & 13,651 \\
\hline Rural High-caste Hindu Landowner & 0.5494 & 4,966 & 2.76 & 5,571 \\
\hline $1-5$ years of education & 0.5460 & 3,783 & 2.79 & 4,212 \\
\hline $\mathrm{OBC}$ & 0.5456 & 6,720 & 2.94 & 7,468 \\
\hline Hindu & 0.5448 & 22,117 & 2.80 & 24,686 \\
\hline Rural Landowner & 0.5447 & 13,066 & 2.90 & 14,692 \\
\hline Works outside home & 0.5441 & 7,165 & 3.15 & 1,846 \\
\hline Employed by others & 0.5437 & 7,590 & 3.13 & 8,271 \\
\hline Rural Landless & 0.5427 & 4,676 & 3.06 & 5,158 \\
\hline $\mathrm{SC}$ & 0.5424 & 4,764 & 3.03 & 5,355 \\
\hline Rich SC & 0.5422 & 636 & 2.63 & 720 \\
\hline Uneducated & 0.5410 & 14,727 & 3.29 & 16,089 \\
\hline Works from home & 0.5330 & 1,665 & 3.00 & 1,846 \\
\hline Poor SC & 0.5378 & 2,504 & 3.24 & 2,790 \\
\hline Poor & 0.5359 & 10,845 & 3.18 & 12,078 \\
\hline Poor, Uneducated, SC, Rural Hindu & 0.5347 & 1,905 & 3.39 & 2,098 \\
\hline Rural Poor & 0.5342 & 10,197 & 3.18 & 11,356 \\
\hline Muslim & 0.5281 & 2,146 & 3.43 & 2,390 \\
\hline ST & 0.5235 & 2,280 & 3.05 & 2,578 \\
\hline
\end{tabular}

Note: This table reports the sample averages for various socioeconomic categories using NFHS-2 data for the 8 sample states. Rich and Poor stand for high and low-SLI, respectively. High-castes are those that are not SC, ST, or OBC. Educated stands for $>6$ years of schooling for a woman. Landownership refers to agricultural land. 
less likely to come from rich SC families. ${ }^{20}$ Together, these findings lend support to Proposition 3(b) and imply that the incentives are less likely to be effective in reducing fertility and decreasing the sex ratio for socioeconomic groups with stronger son preference or lower cost of children that have already given birth to their first child in the absence of incentives.

Table 2-Differences in Characteristics of Couples that Stop After One Child and Those THAT Do Not

\begin{tabular}{|c|c|c|c|c|}
\hline$\overline{\text { Dependent Variable } \downarrow}$ & 1st child is & boy & 1st child is & girl \\
\hline Woman is - & Hry $*$ Post $*$ Stop & Hry $*$ Post & Hry $*$ Post $*$ Stop & Hry $*$ Post \\
\hline Land-owning, Rural, High-caste, Hindu & $\begin{array}{c}-0.0171^{* * *} \\
{[0.0014]}\end{array}$ & $\begin{array}{c}0.0466^{* * *} \\
{[0.0061]}\end{array}$ & $\begin{array}{c}-0.0199^{* * * *} \\
{[0.0010]}\end{array}$ & $\begin{array}{c}0.0300^{* * *} \\
{[0.0056]}\end{array}$ \\
\hline Poor, Rural, SC, Hindu & $\begin{array}{c}0.0432^{* * *} \\
{[0.0090]}\end{array}$ & $\begin{array}{c}-0.0240^{* *} \\
{[0.0077]}\end{array}$ & $\begin{array}{c}0.0421^{* * *} \\
{[0.0065]}\end{array}$ & $\begin{array}{l}-0.0125 \\
{[0.0081]}\end{array}$ \\
\hline Muslim & $\begin{array}{c}0.0224^{* * *} \\
{[0.0049]}\end{array}$ & $\begin{array}{c}-0.0162^{* * *} \\
{[0.0044]}\end{array}$ & $\begin{array}{l}0.0148^{*} \\
{[0.0049]}\end{array}$ & $\begin{array}{c}-0.0143^{* *} \\
{[0.0044]}\end{array}$ \\
\hline$\overline{\mathrm{N}}$ & 117,25 & & 101,093 & \\
\hline Ideal \# children & $\begin{array}{c}0.0908^{* * *} \\
{[0.0155]}\end{array}$ & $\begin{array}{c}-0.025 \\
{[0.0202]}\end{array}$ & $\begin{array}{c}0.1930^{* * * *} \\
{[0.0246]}\end{array}$ & $\begin{array}{l}-0.0836^{*} \\
{[0.0391]}\end{array}$ \\
\hline Ideal \# boys & $\begin{array}{l}-0.0094 \\
{[0.0190]}\end{array}$ & $\begin{array}{l}0.0546^{*} \\
{[0.0292]}\end{array}$ & $\begin{array}{c}0.1579^{* * *} \\
{[0.0238]}\end{array}$ & $\begin{array}{l}-0.0511 \\
{[0.0343]}\end{array}$ \\
\hline Ideal \# girls & $\begin{array}{l}-0.0157 \\
{[0.0197]}\end{array}$ & $\begin{array}{l}-0.0016 \\
{[0.0198]}\end{array}$ & $\begin{array}{c}0.0998^{* * * *} \\
{[0.0198]}\end{array}$ & $\begin{array}{c}0.0796^{* * *} \\
{[0.0116]}\end{array}$ \\
\hline $\mathrm{N}$ & 21,948 & & 19,305 & \\
\hline
\end{tabular}

Note: This table reports the DD and DDD coefficients from a version of specification 1. Each column corresponds to a separate regression. All regressions include state-specific linear time trends and fixedeffects for state, year, and age. Robust standard errors clustered by state are in brackets. The main effect of Stop is included, but not reported. *** $1 \%,{ }^{* *} 5 \%,{ }^{*} 10 \%$.

\section{REFERENCES}

Arnold, Fred, Sunita Kishor, and T.K. Roy. 2002. "Sex-selective Abortions in India." Population and Development Review, 28(4): 759-785.

Bhalotra, Sonia, and Tom Cochrane. 2010. "Where Have All the Young Girls Gone? Identification of Sex Selection in India." IZA Discussion Paper No. 5381 .

Bhat, PNM, and A Zavier. 2003. "Fertility Decline and Gender Bias in Northern India." Demography, 40(4): 637-657.

Dickenmann, M. 1979. "Evolutionary Biology and Human Social Behavior." , ed. N.A. Chagnon and W.G. Irons, Chapter Female Infanticide, Reproductive

\footnotetext{
${ }^{20}$ Regressions using other socioeconomic characteristics as dependent variables yield similar results that are available upon request.
} 
Strategies, and Social Stratification: A Preliminary Model. North Scituate, MA: Duxbury Press.

Goodman, L.A. 1961. "Some Possible Effects of Birth Control on the Human Sex Ratio." Annals of Human Genetics, 25(1): 75-81.

Kim, Jinyoung. 2005. "Sex Selection and Fertility in a Dynamic Model of Conception and Abortion." Journal of Population Economics, 18: 41-67.

Li, Qi, and Juan Pantano. 2014. "The Demographic Consequences of SexSelection Technology." Working Paper.

Oldenburg, P. 1992. "Sex Ratio, Son Preference and Violence in India: A Research Note." Economic and Political Weekly, 27(49): 2657-2662.

Pörtner, Claus C. 2010. "Sex Selective Abortions, Fertility and Birth Spacing." University of Washington, Department of Economics, Working Paper UWEC2010-4-R.

Qian, Nancy. 2009. "Quantity-Quality and The One Child Policy: The OnlyChild Disadvantage in School Enrollment in Rural China." NBER Working Paper 14973.

Tambiah, Stanley J. 1973. "Bridewealth and Dowry: Cambridge Papers in Social Anthropology." , ed. Jack R. Goody and Stanley J. Tambiah, Chapter Dowry, Bridewealth and Women's Property Rights. Cambridge University Press.

Yamaguchi, Kazuo. 1989. "A Formal Theory for Male-Preferring Stopping Rules of Childbearing: Sex Differences in Birth Order and in the Number of Siblings." Demography, 26(3): 451-465. 